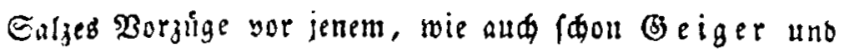
$\mathfrak{B}$ ranoes bemett baben.

\title{
Ueber Das Extractum oleo resinosum Filicis;
}

\section{pom}

Tyotheter Meylin in Debenter, Furenmitglied beß $\mathfrak{B e r e i n g . ~}$

Sa) habe in biefer Beit nuit ber Darfellung bes Ol. Filicis maris mid befáftigt, uno babei eillige Beobadtun: gen gemadt, welde gegen $\mathfrak{B}$ u $₫$ ne $\boldsymbol{B}$ Berfabren aur Darfel: lung biefes Mittelz fpreden mddten. YY efdi er, welder daf: fetbe juerft verfertigte, wandte betauntlid bie $\mathfrak{Y}$ tubjebung ber $\mathfrak{N}$ urjel mit $\mathfrak{A}$ etber daju an. $\mathfrak{B} u$ diner glaubte aber, bas bie Ifajiebung mit 2llebol baffelbe Refultat geben mitre (Re. pert. XXIII). Diefes habe id aber nidet beftetigt gefunten.

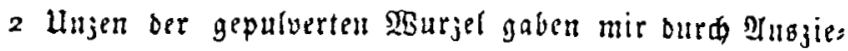

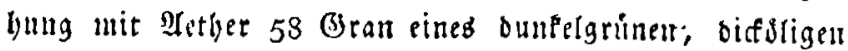

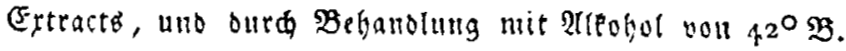

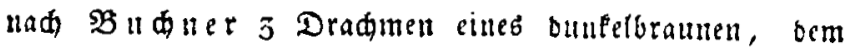
Chinariubenextracte afulidhen Ertractb. Beide Ertracte

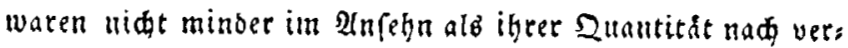
raieben.

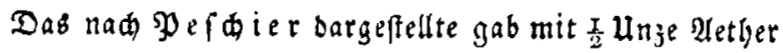
eine belle Dunfelgrune 2lufisfung mit F̧interlaffung einer ges ringen Renge eited pulverigen હtoffb. Die Aluffrung bin:

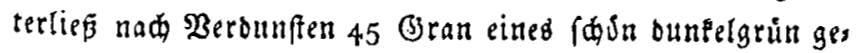
fárbten Stoffí.

Fine Dradme bes nad $\mathfrak{B}$ uda ner bereiteten Stoff tourde mit Ifetber miglidift erfdipft (2 Uujen Aetber surdeu angewandt). (Es entftand feine 2 tufssung, bod nahm 
Die Flúffigleit eine duntelgrủne Farbe an, ber Rliffitand wurbe barauf nod mit $1 \frac{1}{2}$ Unze Hether allgezogen, leķterer

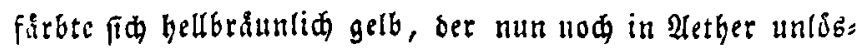
(id) gebliebene Nilffallo war belleraun unb lofte fid in 2 ll: Fohol vollfommen allf. Die obige erfte átberifde Mlufdifung gab burd Berounften 10 Gran eineb febr fetten butterarti: gen Durdfidtigen Stoffs, die jueite 5 Bran eines unburd): fichligen braunlid gelben Farbeftoffs, und bie Alfoholls fung 24 eines extractartigen Stoff3.

Eine anbere Drabme bes lę̧teren Extract wa wurbe mit 4. Unzen deftillirtem $\mathfrak{B a f f e r}$ gef́d, diefes fárbte fic bråun= liđ gelb, unb eine fette ounfelgrune Materie fdramm oar: alt, welde fid in 4 Dradmen Hether aufifte. Diefe Huf= lofung gab ourd freinilliger Berbampfen 6 Gran einer ounfelgrintich braun ourd/feinenden Subftauz. Die wáf: rige 2uflujung wurbe aud verdampft unb biuterlię 30 (Jran eimes ountelbraunen Ertracts, weldes febr bagroglopifd war.

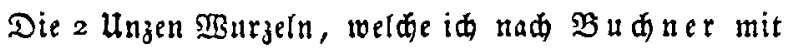
ItFohol belyandelt hatte, wurben hierauf mit 2lether aubges zogen, biefer nabm eine gelbe $\mathfrak{F a r b e} a \mathfrak{n}$, uno gab ourd $\mathfrak{B e r}$ ounften 10 Bran eines gruinen fetten Stoffs, welder fid in 2 Dradmen Mether mit bunpelgrủner Farbe gánjlid altfisfte.

Aus mebreren anbern Berfuden babe id ebenfalls, wie

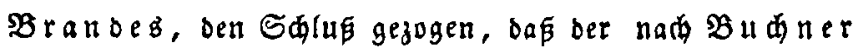

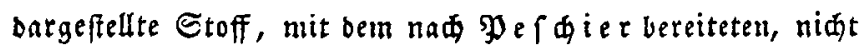
îbereinftimmt; bafi aber aud biefer leştere nod nidt solf: fommen rein iff, uno baßj.bie Bereitungsweife nod mobi. ficirt werden mus, wenn man ben roirkfamen Stoff volfeom, men ifolirt darftellen will. 